\title{
A Digital Ecosystem for the Collaborative Production of Open Textbooks: The LATIn Methodology
}

\author{
Ismar Frango Silveira ${ }^{3}$, Xavier Ochôa ${ }^{6}$, Alex Cuadros-Vargas ${ }^{7}$, \\ Alén Pérez Casas ${ }^{8}$, Ana Casali ${ }^{1}$, Andre Ortega ${ }^{6}$, Antonio Silva \\ Sprock ${ }^{2}$, Carlos Henrique Alves ${ }^{3}$, Cesar Alberto Collazos \\ Ordoñez ${ }^{10}$, Claudia Deco ${ }^{1}$, Ernesto Cuadros-Vargas ${ }^{7}$, Everton \\ Knihs $^{3}$, Gonzalo Parra9 ${ }^{9}$, Jaime Muñoz-Arteaga ${ }^{4}$, Jéssica Gomes \\ dos Santos ${ }^{3}$, Julien Broisin ${ }^{5}$, Nizam Omar ${ }^{3}$, Regina Motz ${ }^{8}$, \\ Virginia Rodés ${ }^{8}$, and Yosly Hernández C. Bieliukas ${ }^{2}$ \\ ${ }^{1}$ Universidad Nacional de Rosario (UNR), Planta Baja, Rosario, Argentina \\ ${ }^{2}$ Universidad Central de Venezuela (UCV), Los Charaguamos, Caracas, Venezuela \\ ${ }^{3}$ Universidade Presbiteriana Mackenzie (UPM), São Paulo, Brazil \\ ${ }^{4}$ Universidad Autónoma de Aguascalientes (UAA), Aguascalientes, Mexico \\ ${ }^{5}$ Université Toulouse III - Paul Sabatier (UPS), Toulouse, France \\ ${ }^{6}$ Escuela Superior Politécnica del Litoral (ESPOL), Campus Gustavo Galindo - CTI, \\ Guayaquil, Ecuador \\ ${ }^{7}$ Universidad Catolica San Pablo (UCSP), Campus Campiña Paisajista s/n Quinta \\ Vivanco, Arequipa, Peru \\ ${ }^{8}$ Universidad de la República (UdelaR), Montevideo, Uruguay \\ ${ }^{9}$ University of Leuven (KU Leuven), Leuven, Belgium \\ ${ }^{10}$ Universidad del Cauca (Unicauca) FIET, Setor Tulcan, Popayán, Colombia
}

\section{Executive Summary}

Access to books in higher education is an issue to be addressed, especially in the context of underdeveloped countries, such as those in Latin America. More than just financial issues, cultural aspects and need for adaptation must be considered. The present conceptual paper proposes a methodology framework that would support collaborative open textbook initiatives. This methodology intends to be the main guideline for a digital ecosystem for the collaborative production of open textbooks and has the potential to solve standing methodological problems of current initiatives, such as Wikibooks and Connexions. The system's architecture and construction will be

Material published as part of this publication, either on-line or in print, is copyrighted by the Informing Science Institute. Permission to make digital or paper copy of part or all of these works for personal or classroom use is granted without fee provided that the copies are not made or distributed for profit or commercial advantage AND that copies 1) bear this notice in full and 2) give the full citation on the first page. It is permissible to abstract these works so long as credit is given. To copy in all other cases or to republish or to post on a server or to redistribute to lists requires specific permission and payment of a fee. Contact Publisher@InformingScience.org to request redistribution permission. guided by six collaborative writing dimensions: process, roles, timing, controlling, granularity, and writing groups. Each dimension will coordinate an aspect of the collaborative work and is detailed in the methodology proposed in this paper.

This paper is divided in the following parts: the first part introduces the subject, being followed by an analysis of 
related works about collaboration and Computer-Supported Cooperative Work; in this section, some authors, ideas, and methodological aspects of collaborative writing are also discussed. Next, the paper shows the proposal of a Digital Ecosystem for the collaborative creation of open textbooks, the six dimensions of this Ecosystem, and its respective descriptions. The work finishes with some conclusions about the proposal and the next steps needed to implement it in the real world.

Keywords: collaborative writing, textbooks, LATIn project, Latin America, universities, digital ecosystem, Wikibooks, Connexions, Open textbooks, Open license, Copyleft, Creative Commons

\section{Introduction}

The regular process for book production is often regarded as a set of procedures with a welldefined, ordered progression from beginning to ending. Content producers following different strategies can write, edit, and publish books. The product of this activity is the final textbook in a largely fixed form. This model for textbook production is heavily based on historical copyright practices and writing tools available when it was first implemented.

New approaches to content licensing and sharing, as well as new collaboration tools, have opened opportunities for new ways of producing collaborative textbooks. Previously, standard copyright rules forbade the copying of any part of a book, forcing authors of textbooks to find different ways to express the same ideas, even if they were writing about widely known topics, in order to avoid infringing these rules. On the other hand, new open licenses, such as Copyleft or Creative Commons, permit the reuse and adaptation of parts or even complete books. This means that if a textbook with an open license contains a good explanation of a topic, it can be reused in other textbooks. Furthermore, if that explanation is not good enough for the new content producers, they are allowed to change it without asking for permission to the original producer.

One of the causes of the low adoption of collaborative writing is the fact that, some years ago, the technology available was limited. It was hard to find textbooks produced by more than 4 or 5 authors. Usually, each author contributed his or her part, an editor checked for consistency and coherence, and the final version was produced. This writing strategy is known as "Separate Writers" and it was widely used, due to the nature of the tools available. Most of these tools were simple word processors, making truly collaborative writing impracticable, since it would be impossible to have everyone working in all parts of the document at the same time and still maintain both thematic coherence and version management of the different writings. The development of more sophisticated collaborative writing tools, such as wikis, and synchronous applications like Google Docs, allows seamless collaboration on long documents, where every author can contribute in throughout the document without losing reference versions. The use of these more sophisticated tools increases the number of potential contributors without turning collaboration management into a complex activity. Both types of innovations described here, legal and technological, have the potential to revolutionize the way in which textbooks are produced.

One characteristic of the traditional textbook production model is that the only acceptable final product is a complete book. If a content producer had materials and ideas for a single chapter or section, this producer would not be able to publish them. The talent of these small producers is not leveraged in the process, thus diminishing the potential quality of the resulting textbooks. Consider the possibility of having textbooks created by a large group of authors, each one specializing in one or more topics. The consistency and coherence of collaborative textbooks could be managed not only by an editor, but also through peer-reviews and continuous cross-evaluation. This new approach also has the potential to produce higher quality textbooks than the traditional model does. 
However, adding open licenses and new technologies is not enough to bootstrap a different process of textbook production. Collaboration strategies and methodologies should be in place, in order to guide the textbook production groups. However, after an exhaustive literature review, no conceptual frameworks were found to support collaborative writing processes, especially when dealing with open textbooks as the main products of such processes. This is the knowledge gap that this paper proposes to fill. This work is a conceptual paper, and as such it does not aim to present any results of empirical studies or experiments. Instead, our major goal is to propose a framework of collaboration strategies and methodologies, describing the concept of a digital ecosystem for collaborative open textbook production.

\section{Related Work}

In this section, Collaboration and Computer-Supported Cooperative Work (CSCW) is introduced. Then we focus on analysis of the literature relating to experiences with collaborative writing of textbooks.

Collaboration has been a way for humans to do things from ancient times. Technology advances facilitate communication and information sharing in digital formats and seem to have a positive impact on our tendency to collaborate, probably because it is cheaper and faster for us to communicate now than it was before, and it is much easier to share digital objects than physical ones. From software freedom initiatives to more recent movements towards freedom of other digital artifacts, and nowadays Web 2.0 phenomena, people have met in digital spaces and have used digital tools and media to create digital materials that can be shared among themselves and with others. The literature provides many definitions for collaboration, but we restrict ourselves to Patel, Pettitt, and Wilson (2012), which describes collaboration as a community activity that coordinates itself to communicate and achieve common goals.

Computer-Supported Cooperative Work is a computer-assisted coordinated activity carried out by groups of collaborating individuals (Baecker, Grudin, Buxton, \& Greenberg, 1995). CSCW is a very broad interdisciplinary area, where we can find different software available to support collaboration. One type of such software is groupware, computer-based systems that provide an interface to a shared environment in order to support groups of people working on a common task. The collaborative creation of open textbooks falls into the realm of study of CSCW and more specifically makes use of collaborative writing groupware tools.

We primarily are interested here in such topics as how the team in charge of a book creation is formed, the different roles in the group, how the work is distributed, how different versions are managed, and what authoring policies are used. Unfortunately, there is sparse literature in this area. However, we have reviewed different successful projects and experiences related to the collaborative creation of books, and, below, we present a brief description of the most relevant works for our purpose. We begin by considering the two most important initiatives that propose tools and methodologies to enable authors to produce books: Wikibooks and Connexions.

\section{Wikiboooks}

Wikibooks is a Wikipedia project that started in 2003. It presents the same editing interface than Wikipedia (Ravid, Kalman, \& Rafaeli, 2008). According to Frith (2009), Wikibooks has four key problems related to the methodology used:

- Accuracy: Any author could modify the textbook created by the original author without creating a new version of it. This allows the possibility that good content could be replaced by bad content. 
- Collaboration: There is much less collaboration than in Wikipedia. The books are mainly the product of one author or a small number of authors.

- Length: The article format that works well for Wikipedia does not adjust to the length of a complete textbook.

- Attribution: There is little recognition for the authorship and it is not explicit. The authors in this system do not have any control over their content and do not receive specific credit for their work.

Despite these limitations, the wiki format has been used in valuable projects. Hohne, Fu, Barkel, and Woolf (2007) present an approach to teaching whereby students and faculty collaborate to explore subject matter through the creation of articles for an open-source textbook viewable using the wiki format. In this approach, teams of students wrote sections of a new textbook for a senior level Chemical Engineering Process Controls course. The writing and presenting of articles provide opportunities for students to learn by teaching. Each article was formally reviewed by other students in the class to give suggestions and correct errors. Throughout this process, the instructors acted as advisors, gave the general topic outlines, provided reference material and made connections between various student topics. Hohne et al.'s paper presents evidence of the good results of this approach in the form of standard course evaluations. Another similar experience is detailed in Ravid et al. (2008), where wiki technology was applied to the development of an introductory academic textbook on information systems, which was written collaboratively by faculty and students and was made available online free of charge. After about two years of activity, the wikitextbook accumulated 564 sub-chapters, co-authored by undergraduate and graduate students in more than 20 classes offered by Israeli universities. Authors of this research discuss the potential of wiki textbooks as vehicles of empowerment to students, teachers, and the discipline.

\section{Connexions}

Unlike Wikibooks, Connexions is a collaborative writing platform and a repository at the same time. In Connexions, users are free to create educational materials and contribute to the repository; copy and customize materials; mix them together to produce new books and courses; and to create finished products like e-learning web courses or printed books (Dholakia, King, \& Baraniuk, 2006). The production of content in Connexions has a modular format where the user needs to register to be able to create a module. In order to modify one of these units created by another user, the author needs permission of the original writer, or they must split off a new version. The authors of a module are always mentioned at its beginning. The main limitations found in Connexions for the production of Collaborative Textbooks are:

- The Connexions community is driven by modules, not entire books. While having loose materials is beneficial for the creation of textbooks, often this material remains loose and is not ultimately coordinated with other modules to produce a cohesive book.

- Collaboration: While modules are created collaboratively, most of the books that are created (called collections) have a single author.

- Edition: When books are created that include work by diverse authors, those books are often just a collection of modules, without continuity.

- Concurrency: There is no control for the concurrency. If two authors open the same part of the text, the changes preserved are only from the one that saved last.

Baker, Thierstein, Fletcher, Kaur, and Emmons (2009) present a proof-of-concept via Connexions. Their research shows the feedback returned by professors and students explaining each of the lessons learned about open textbook production. Challenges to the production and adoption of 
open textbooks include (1) faculty members' and students' expectations of high production quality, (2) the need for methods for documenting and maintaining control over various versions, and (3) the need for better processes for converting existing open content to digital and accessible formats. Baker et al. identified lessons learned about open textbook production, emphasizing the importance of interactivity, assembly-line workflow, a style guide and naming conventions, and standard mathematical authoring tools.

\section{Additional Relevant Work}

Horner and Blyth (2008) present a project to address the massive shortage of accessible and affordable educational resources in South Africa. The vision of the project's founders was to write textbooks in a collaborative way using contributions from many volunteers. They describe attempting to get a core multi-skilled team following cohesion-oriented guidelines, and the need for clear role definition. These authors also emphasize the importance of open and regular communication between team members. During the main content creation phase of the project, they held weekly meetings among team members. These meetings were always run with an agenda and included feedback sessions as well as team brainstorming sessions.

Henderson and Nelson (2011) describe Orange Grove Text Plus, a joint initiative of the University Press of Florida and the Orange Grove repository. This article presents a detailed plan to promote open access textbooks and their use in Florida. This plan addresses six essential components: strategies for production and distribution, Open Textbook production and review protocols, awareness campaign, adoption and use, system security, and sustainability. In particular, the two first components are related to methodologies. The authors found that the factors involved in the development of open materials were, in order of priority: 1) time to review, find, select materials; 2) hardware and software to facilitate development; 3 ) desire to reduce student costs; 4) assurance that their materials are peer-reviewed and edited; 5) availability of the review criteria to the authors; and 6) administrative support for efforts.

\section{Issues Raised by Past Work}

From the literature analysis, it can be concluded that collaborative writing is still a process being rediscovered by each group involved in the task. There are some guidelines, such as the ones presented by Posner and Baecker (1992), but their general nature makes them more useful to analyze existing collaboration than to guide the development of a methodological strategy. The advent of whole new ways to communicate and interact, brought by the advent of Web 2.0 technologies, reopens the discussion about how to organize successful collaborative writing groups. From the experiences mentioned above, we can recognize that the first task to face in the collaborative writing of open textbooks is to establish the working group. Some authors recommend a small core team of well-motivated persons, where the different roles and responsibilities can be defined clearly. Fluent communication between participants is one of the main factors cited for success. Besides, some standardization may be defined, as, for example, a style guide and the use of specific math authoring tools. It can be concluded that the range of strategies varies accordingly to the needs and context of each initiative. There is at present no overall methodology that could be useful in every case and situation.

\section{Goals of the Current Paper}

Our proposal of a digital ecosystem for the collaborative creation of open textbooks is designed to be adaptable to different working groups, incorporate recent collaboration types derived from new Internet technologies, and address the limitations and recommendations of prior researchers. We now present our guidelines for the collaborative work of content and book creation groups. 


\section{An Ecosystem for the Collaborative Creation of Open Textbook}

This work proposes the idea of a digital ecosystem to help to model and guide the collaborative creation of open textbooks. An ecosystem is a community of organisms in conjunction with environmental components interacting as a (semi-) closed system. These interactions form a network of interchanges of resources and energy that define such an ecosystem. The adaptation of the ecosystem concept to collaborative networks in the digital world has produced the term digital ecosystem.

A digital ecosystem is an artificial system that aims to harness the dynamics that underlie the complex and diverse adaptations of living organisms in biological ecosystems (Briscoe \& De Wilde, 2006). A digital ecosystem transcends the traditional rigorously defined collaborative environments from centralized or distributed or hybrid models into an open, flexible, domain cluster, demand-driven, interactive environment (Chang \& West, 2006). A digital ecosystem is an open community, and there is no permanent need for centralized or distributed control or for single-role behavior. In a Digital Ecosystem, a leadership structure may be formed (and dissolved) in response to the dynamic needs of the environment (Boley \& Chang, 2007).

The first component of any ecosystem is the environment and its inert components. In this analogy the producers and the content are the main resources that form the environment. The producers are the individuals that are able to transform ideas into multimedia elements. Content is any digital construct that could be used to teach or learn an idea or concept.

The second component of the ecosystem is the living organisms, grouped in species. These organisms take energy and resources from the environment and use them to grow and live. These organisms could also produce or transform the resources that can later be the input for other organisms. For this analogy, we have two main species in the collaborative creation of open textbooks ecosystem: the book producing group and the content producing group. The groups are an aggregation of producers working on an idea. If the idea is the creation of a book, the group is usually large and the desired output will be a complete book on a given topic. If the idea is the creation of an individual piece of content, as in coverage of one topic, then the group usually will be small and the output will be simply discrete learning materials. It is interesting to note that contentdriven organisms could live inside book-driven organisms or by themselves in the environment.

The cycle of this book-creation ecosystem starts when a number of producers in the environment decide to come together to create a book on a given topic. These producers bring to life the bookdriven group that, if succeeds, will produce a book. Another way in which the cycle could start is when an individual producer (or a small group of producers) decides to create a discrete learning content. In this case, a content-driven organism is created with the goal of producing such learning material.

The book-driven organism will be the main consumer of this ecosystem. It will integrate new producers that want to contribute and also will use existing content in order to produce the book. To assimilate the existing content, the book-driven organism will rely on a smaller content-driven organism to adapt this content to the needs of the book. Also the content-driven organisms inside the book-driven one will be able to create new content that is given back to the environment. The book-driven organism, when the initial idea has been fulfilled, will generate a book. Figure 1 shows the collaborative writing process, beginning with the group formation and ending with writing the textbook. Any group could create new versions of the book. 


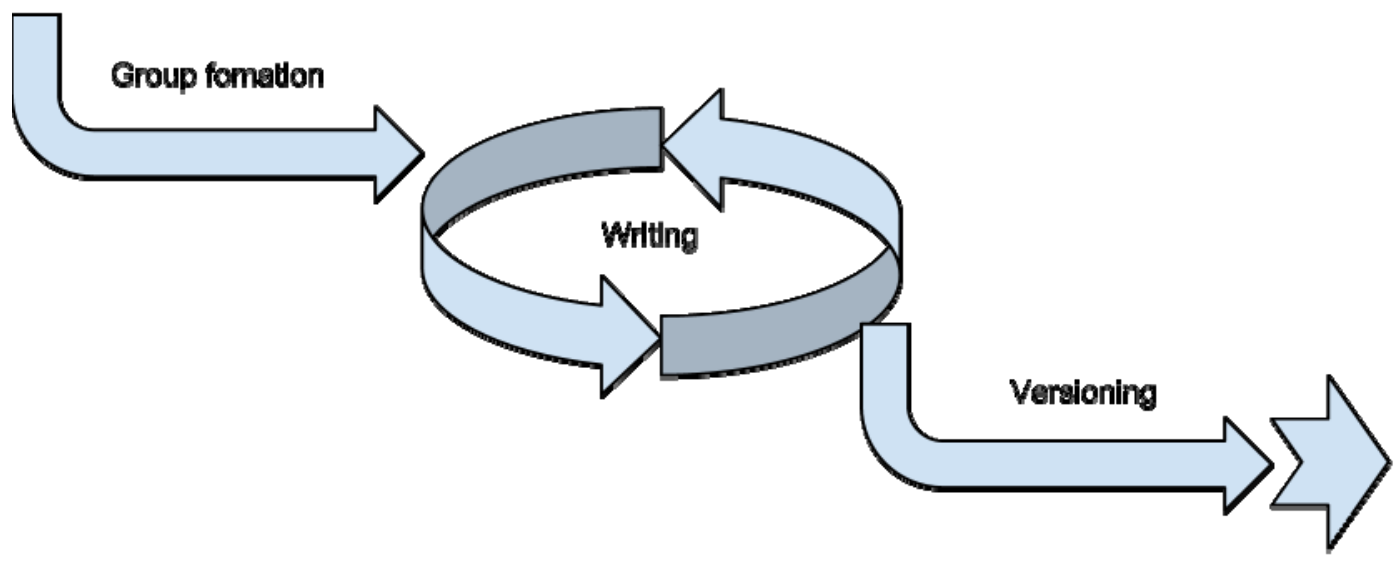

Accreditation

Figure 1: Collaborative writing process

A massive collaboration, called "crowdsourcing" occurs in the ecosystem. The term was coined by Howe (2006). Crowdsourcing is a production model that uses the collective intelligence and knowledge of volunteers across the Internet to solve problems and generate solutions, for example for the development of new technologies or, in this case, for content creation. This concept, together with the "long tail" concept (which points out that the aggregate value of a quasi unlimited set of low-demand undervalued elements usually is higher than the sum of values of a limited set of high-demand most valued elements) are generating a new way of dealing with things apparently distinct (like goods being sold by an e-commerce website and content being delivered through the Internet) that, in fact, share the same essence (Ochoa, Silva-Sprock, \& Silveira, 2011).

Figure 2 shows the writing process, which includes new environmental trends, target definition, activities definition, needs adaptation, storage, and evolution of knowledge groups' identification. The groups and tools involved in the writing process are the knowledge groups involved in technological, pedagogical, and content aspects, advisory groups and critics, the distribution platform, and the tools used for authoring and production.

This initiative will encourage and support local professors and authors to contribute individual sections or chapters that could be assembled into customized books by a larger community. The created books will be freely available to the students in an electronic format or could be legally printed at low cost because there is no license or fees to be paid for their distribution. This solution will also contribute to the creation of customized textbooks where each professor could select the sections appropriate for their courses or could freely adapt existing sections to their needs. For the community to function effectively, it will need to provide peer evaluation and recognition to the best authors, as well as support communities for discussing teaching strategies and resources. Also, local professors will be the sink and source of the knowledge, contextualized to the Latin American Higher Education system. The quality of the produced open textbooks could be similar or better than the quality of traditional texts. 


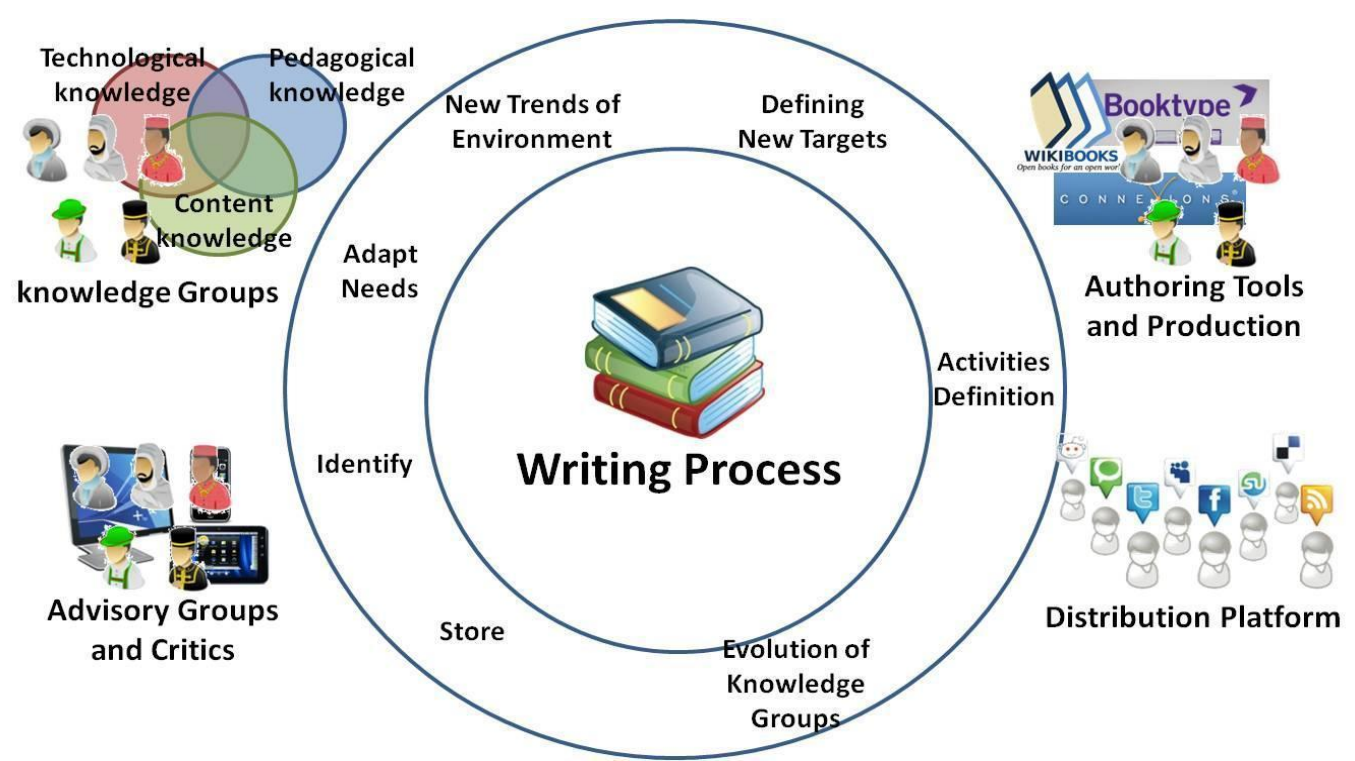

Figure 2: A digital ecosystem for the collaborative production of open textbooks

The creation of a book does not mean the death of the book-driven organism. The book's content producers could continue to improve or adapt the book, producing new versions (in a similar way in which a natural organism could have several offspring). When finally a book-driven group is dissolved, its members can become part of new groups in a way that simulates the natural recycling on a natural ecosystem.

The book-driven organisms, and to a lesser extent the content-driven organisms, are organized according to a group of guidelines that allow them to function as groups. These guidelines should provide methods to conduct the main activities of the group, for example, how the group is organized, which roles that the different authors will have during the writing and editing periods, and who will make the decision for publishing a version of the book. The following section presents these guidelines grouped in six dimensions.

\section{The Six Dimensions That Guide the Ecosystem}

The collaborative processes of producing textbooks with shareable content must incorporate different dimensions, ranging from organizational dimensions to technical ones. As shown in Figure 3 , six dimensions were identified from an analysis of the literature, the context for LATIn Project, and the new requirements identified therein. We now briefly describe each dimension, before considering each one individually in more depth.

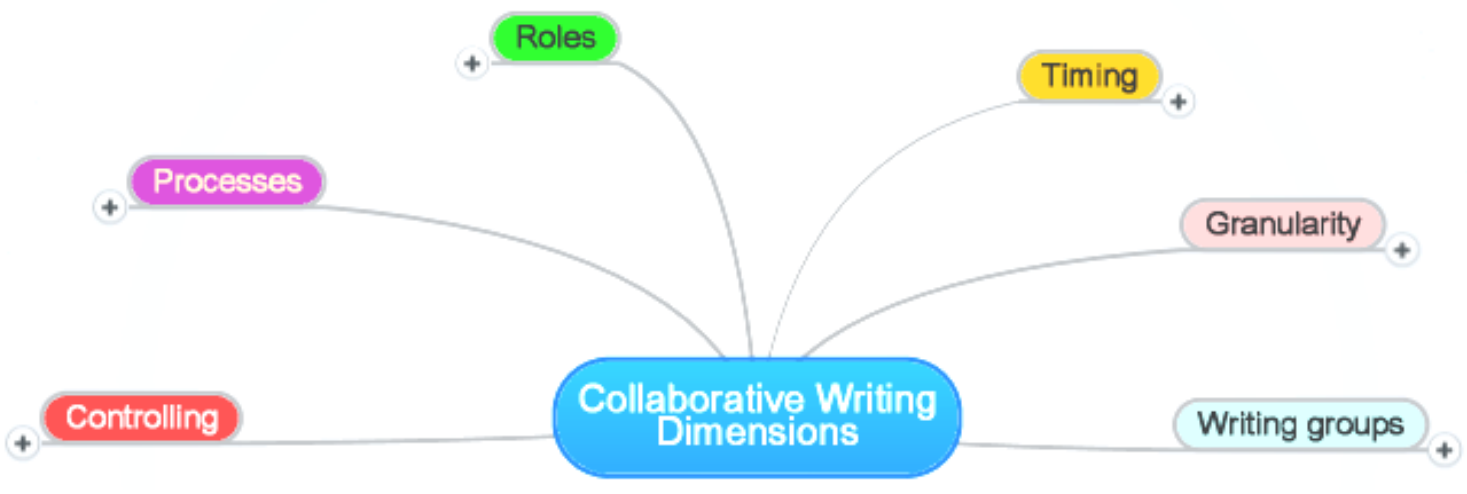

Figure 3: The Digital Ecosystem's six dimensions 
- Processes: This dimension embraces the set of activities that are meant to be developed when creating, reusing, or remixing separated content or entire books. Group-organizing, producing, publishing, accreditation, and Content-driven activities are the sub-categories of this dimension. The latter sub-category includes specific activities related to textbook writing, such as brainstorming, planning, researching and finding content, content producing, reusing and remixing, content organization, reviewing, releasing, and templating.

- Roles: By allowing reusing and remixing, the producing process goes beyond traditional writing process, which means that traditional roles - like writers, reviewers, editors, and authors - must be reconsidered. New roles, together with some traditional ones, are present in this dimension, such as Content Producers; Idea Generators; different types of Reviewers according to the contents or aspects such as, Technical, Pedagogical and Language; Organizers; Template Designers (Interface and Pedagogical), Accreditators, and Translators.

- Timing: This dimension concerns the time when new content is meant to be produced or remixed/reused. Since these are two different processes, the timing dimension is majorly divided into two branches: writing time and remixing time.

- Control: This dimension is already well-defined in literature and fits to the project's needs. It deals with the controlling mechanisms of the writing process, which are the same for the create/reuse/remix triad. The different types of controls considered are centralized control, relay, independent, and shared. Control could be assumed by some roles and could change in different process phases.

- Granularity: Refers to the amount of information on a content topic. More information inside some piece of content leads to more coarse granular elements, while a little amount of information encapsulated by content elements brings more reusable, fine granular objects, whilst they tend to be less context-aware. This dimension is extremely important in the domain of open books.

- Writing groups: This sixth dimension recognizes the way people are organized, or organize themselves, to collaboratively produce content. The organization for this dimension proposed here adapts a previously presented organization scheme, adjusting it to the needs of the present project.

\section{Processes Dimension}

More than just a simple aggregate of rich media content, book production involves a wider spectrum of processes, from group-related activities (group formation, task and roles assignation), to publishing and accreditation, as well as the creative processes themselves. Allowing the creation and management of separated, fine-granular pieces of context, the main process proposed by LATIn ecosystem is undoubtedly book-driven. Thus, all content-related activities are also enclosed in book-related ones. Figure 4 shows this dimension. 


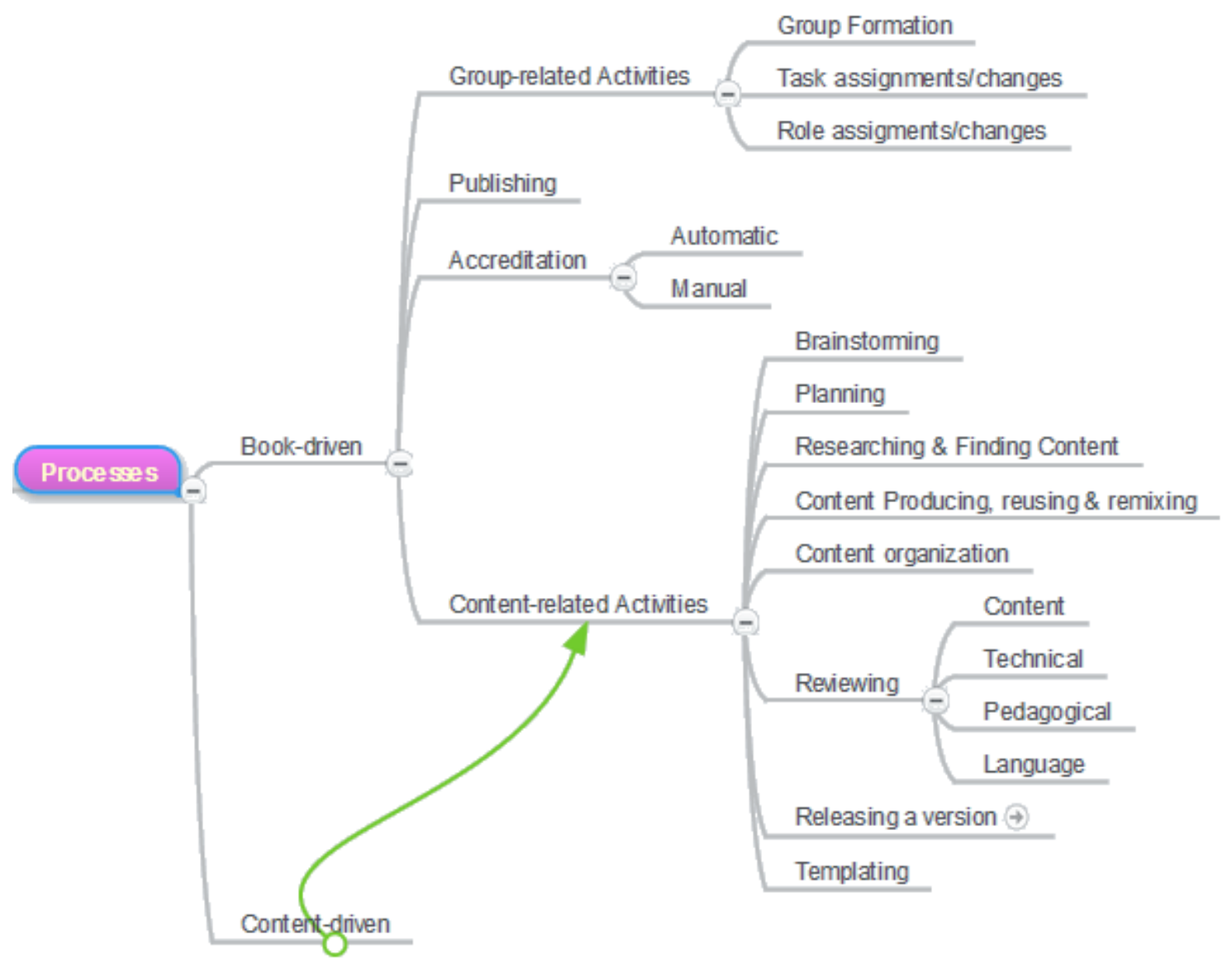

Figure 4: Process dimension

The so-called Book-driven activities include:

- Group-related activities, including group formation strategies (by invitation, autoinvitation, open groups, and so on) and the assignment of tasks and roles (which could be auto-assigned or assigned by persons with coordinating roles). Roles, tasks, and the group itself could be changeable during the book production process.

- Publishing, with the meaning of creating "frozen" versions of the books and dealing with its distribution.

- Accreditation, referring to the process of certifying and approval of a version of the book. This process could be administered by a person or an organization, being done in a manual way, which means that each book version must be under a dedicate accreditation process, or (semi) automatic, when accreditations are given according to the author's profile and previous accreditation.

As noted earlier, content-driven activities are enclosed in book-driven ones. They include:

- Brainstorming: more than a group dynamics technique, brainstorming in the current context is a process that must be undertaken to explore the creativity of a person or a group.

- Planning is one of the most important processes, since it is essential to decide characteristics of the content that will be covered, such as aspects, approach, information that are vital for the purpose of the book. 
- Research and finding content: once the planning process is done, the person (or group) involved in this task has to conduct a research on the content, taking into account what was previously decided.

- Content producing could be realized in some different ways such as writing entirely new content based on the person's (or group's) previous knowledge and/or the research that was done, reusing some content that matches the objective of the book or remixing this content by adding information, or changing the structure in which the content was originally created.

- Content organization gives cohesion, in other words, organizes the different pieces of content produced for the book and puts it into an understandable form, since the content was collaboratively written by people with different writing styles.

- Reviewing can be done from different perspectives and at different times: content reviews determine whether the content covers the objectives; technical reviews focus on the text, graphics and images; pedagogical reviews consider whether the content is structured in a sound pedagogical manner; language reviews check spelling and grammar.

- Versioning refers to the process of "freezing" the content and organization of a book to release it. Professors will be able to establish their own book versions in order to use them in their syllabus, for instance.

- Templating covers the creation, reusing, and remixing of interface templates for applying to individual content or the entire book. This process is related to a specific role, the Template Designer (see next section), and this task can be accomplished in two different ways: interface templating deals with aesthetic features of text and rich media presentation; pedagogical templating refers to the ways the content is organized and exposed to readers. This last type of templating is extremely important to establishing good pedagogical practices. Pedagogical practices generally can be shared among Latin American countries, whose pedagogical context already has some important similarities.

\section{Roles Dimension}

In order to promote efficiency and allow people to take initiative in the core team, it is important to have clearly defined roles in a multi-skilled team. In this section, we propose a set of roles for collaborative writing. Some of them are taken from the production of traditional books and are adapted to this new context. Others are defined to include the different roles in the whole process, from group creation to accreditation, for book-driven and content driven activities. The roles required to make a successful core team are shown in Figure 5 and include the following:

- Content Producer: this role represents a person or a group that uses various methodologies stemming from collaborative writing to create content about a specific topic.

- Idea Generator: this person (or group of people) identifies the big picture of the project, leads the others towards the main objective, and keeps the momentum of the project moving forward.

- Reviewer: there are four major types of reviewer:

- Content Reviewer: this role is in charge of reviewing the content about a specific subject. This person (or group) must work closely with the Content Organizer, proposing the appropriate modifications. 
- Technical Reviewer: this role has the function of checking all the technical aspects of the book or content, for example, checking the consistency of the links, revising the formulas, etc.

- Pedagogical Reviewer: this person ensures that the organization of the content (see below) will make sense from a pedagogical point of view, hence, works closely with the content organizer in order to identify missing contents or elements that must be investigated more deeply.

- Language Reviewer: a native speaker has to review the book in order to ensure that its spelling, syntax, and grammar conform to the target language.

- Organizer: having someone on the team who is a good organizer is very useful since things always arise that need to be done and for which details and planning are important. We consider two roles:

- Content Organizer: a person able to guide the creation of a book, who has clear insights into curriculum needs, while providing swift feedback on all aspects of the contents. Also, he/she proposes the table of contents and will define the collaborative writing strategy for the group.

- Group Organizer: this role is vital in order to organize the team that works on the project. The person in charge of this role should be characterized by various competencies, including project management, relationship management, experience within the field of collaboration, and basic knowledge regarding the topic of the book. Since managing the entire team can be very time consuming, we recommend one full-time coordinator per book.

- Template Designer: Again, we consider two roles:

- Interface: this designer develops and maintains the template of each book to make sure that the content produced by the various collaborators (content producers) match in terms of look-and-feel. This person also is responsible for designing and implementing any required improvements in a short period of time.

- Pedagogical: the pedagogical template designer offers a uniform way to fill the table of contents established by the content organizer and ensures that the content of the various chapters is organized according to a common structure that follows a pedagogical strategy.

- Accreditator: This is a person or an organization that validates each book against a given level of quality assurance. In our context, the accreditator validates the quality of the book according to the content, technical, pedagogical, and language points of view. Accreditation includes a peer review process to guarantee that the books meet the needs of Latin American students and takes place after the work of the reviewers described above. Once the accreditation has been established, the books can be disseminated to the target audience.

- Translator: when the native language of the content producer does not match with the language of the intended audience, the translator ensures appropriate translation of the content into the target language. After this process, the translation still has to be validated by the language reviewer. This role is crucial for the Latin American context, with its two major languages: Spanish (around 360 million native speakers in the region) and Portuguese (circa 200 million native speakers in Brazil). 


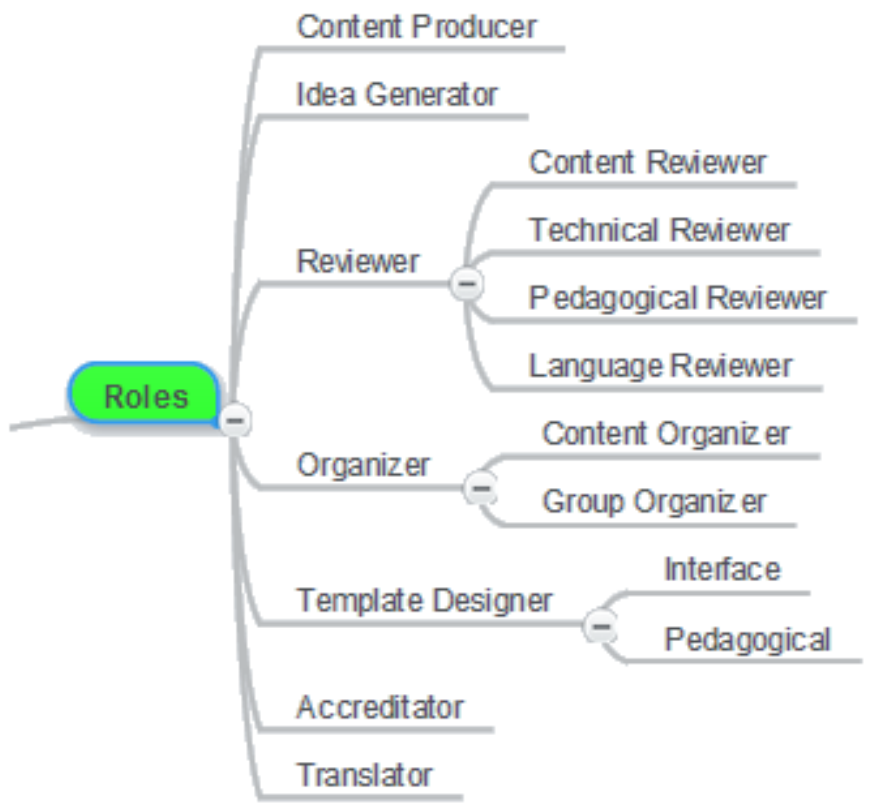

Figure 5: Roles dimension

We believe that these are the main roles to be considered for both content-driven and book-driven processes. In the former case, the group may be small and one person may assume different roles. In the latter case, with a bigger group, roles can be distributed and a single role can be assumed by different people.

\section{Timing Dimension}

The timing dimension is divided in two main branches: writing time, focused on the production of brand new content, and remixing time, when the reuse and remix actions will occur. Figure 6 shows this division.

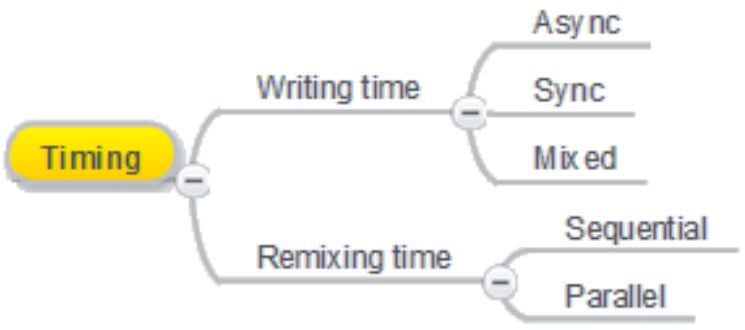

Figure 6: Timing dimension

The definition of writing time is important for organizing the collaboration of participants in the production of open textbooks, and it can be handled in synchronous, asynchronous, or mixed ways. The writing time in synchronous form, according to Ferreira (1986), involves occurrences at the same time, narrating, explaining, describing, and making the action simultaneous. Asynchronicity occurs when things do not occur simultaneously. In asynchronous communication, participants collaborate on writing content and interact without regard to time. According to Cabeda (2005), asynchronous writing times give flexibility to the participants, providing greater freedom for the individual to set the time of their participation, as well as the depth of their reflections. 
Remixing time can be parallel to the production of some content (content is being remixed whilst it is still being created) or sequential (which means that content is already done and is remixed after its publication - which leads to the classical idea of reuse).

\section{Control Dimension}

Controlling involves managing the processes related to collaborative writing of open textbooks. Posner and Baecker (1992) have proposed a classification of four types of controlling for the writing process. We have extended that classification to a general process related to collaborative writing of open textbooks, as shown in Figure 7, to include the following:

- Centralized, one person controls the process during the whole project;

- Relay, one person at a time controls the open book, but it is not always the same person. The controlling relay is planned from initial phase;

- Independent, each person controls the section on which he or she is working;

- Shared, every role has equal access to the open textbook.

These methods are not fixed; they usually change at different stages of the writing process (Noel \& Robert, 2004). In a Latin American context, teachers in general prefer independent work, where the process for writing an open textbook would be distributed; however, shared controlling may be the best option in order to maintain steady control of work and still allow authors a strong sense of authorship.

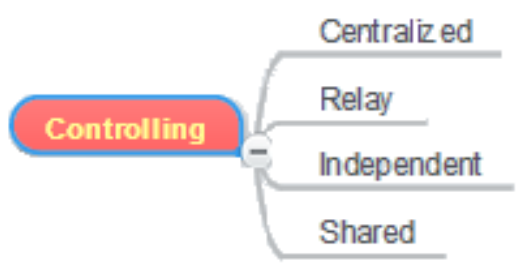

Figure 7: Control dimension

Posner and Baecker (1992) applied a survey, and they found a relationship between the process control method and writing groups. For example, their respondents answered that the separate writers strategy was used with different types of control: independent, relay, or shared. However, the first method was the most effective under these circumstances. When respondents used the single author strategy, their process control method was almost always centralized, except for two cases where access to networked computers gave rise to shared control. Finally, respondents doing joint writing used either shared, relay, or independent control, the last one proving to be the least effective under these circumstances.

Since the process dimension is related to the collaborative writing of open textbooks, we consider the relation between the role and controlling dimensions, while recognizing that the roles can have different types of control in different process phases. Table 1 describes the different types of controls (Centralized, Relay, Independent, and Shared). Each role could be assumed in different phases of the process, where according to the established control it is possible to realize different activities. Consider, for example, such portions of the process as Producing Content, Reusing, Remixing, Brainstorming, and Reviewing. Notably, in the first process phase (group formation), it is necessary to apply centralized controlling. 
Table 1: The Relationships between Roles, Control and Processes

\begin{tabular}{|c|c|c|c|c|}
\hline $\begin{array}{l}\text { Role / Control- } \\
\text { ling }\end{array}$ & Centralized & Relay & Independent & Shared \\
\hline $\begin{array}{l}\text { Content Pro- } \\
\text { ducer }\end{array}$ & $\begin{array}{l}\text { CRAContent/ } \\
\text { Producing, } \\
\text { reusing \& } \\
\text { remixing }\end{array}$ & $\begin{array}{l}\text { CRA/Researching \& } \\
\text { Finding Content; } \\
\text { CRA/Content } \\
\text { Producing, reusing } \\
\text { \& remixing }\end{array}$ & $\begin{array}{l}\text { CRA/Researching } \\
\text { \& } \\
\text { Finding Content; } \\
\text { CRA/Content } \\
\text { Producing, reusing } \\
\text { \& remixing }\end{array}$ & $\begin{array}{l}\text { GRA/Group } \\
\text { Formation; } \\
\text { CRA/Brainstorming; } \\
\text { CRA/Researching } \\
\text { \& } \\
\text { Finding Content; } \\
\text { CRA/Content } \\
\text { Producing, reusing } \\
\text { \& remixing }\end{array}$ \\
\hline Idea Generator & $\begin{array}{l}\text { GRA/Group } \\
\text { Formation }\end{array}$ & $\begin{array}{l}\text { CRA/Brainstorming; } \\
\text { CRA/Researc bins } \\
\text { \& } \\
\text { Finding Content }\end{array}$ & $\begin{array}{l}\text { CRA/Brainstorming; } \\
\text { CRA/Researching } \\
\text { \& } \\
\text { Finding Content }\end{array}$ & $\begin{array}{l}\text { CRA/Brainstorming; } \\
\text { CRA/Researching } \\
\& \\
\text { Finding Content }\end{array}$ \\
\hline \multicolumn{5}{|l|}{ Reviewer } \\
\hline Content & $\begin{array}{l}\text { CRA/Reviewing/ } \\
\text { Content }\end{array}$ & $\begin{array}{l}\text { CRA/Reviewing/ } \\
\text { Content }\end{array}$ & $\begin{array}{l}\text { CRA/Reviewing/ } \\
\text { Content }\end{array}$ & $\begin{array}{l}\text { CRA/Reviewing/ } \\
\text { Content; } \\
\text { CRA/Releasing a } \\
\text { version }\end{array}$ \\
\hline Technical & $\begin{array}{l}\text { CRA/Reviewing/ } \\
\text { Technical }\end{array}$ & $\begin{array}{l}\text { CRA/Reviewing/ } \\
\text { Technical }\end{array}$ & $\begin{array}{l}\text { CRA/Reviewing/ } \\
\text { Technical }\end{array}$ & $\begin{array}{l}\text { CRA/Reviewing/ } \\
\text { Technical; } \\
\text { CRA/Releasing a } \\
\text { version }\end{array}$ \\
\hline Pedagogical & $\begin{array}{l}\text { CRA/Reviewing/ } \\
\text { Pedagogical }\end{array}$ & $\begin{array}{l}\text { CRA/Reviewing/ } \\
\text { Pedagogical }\end{array}$ & $\begin{array}{l}\text { CRA/Reviewing/ } \\
\text { Pedagogical }\end{array}$ & $\begin{array}{l}\text { CRA/Reviewing/ } \\
\text { Pedagogical; } \\
\text { CRA/Releasing a } \\
\text { version }\end{array}$ \\
\hline Language & $\begin{array}{l}\text { CRA/Reviewing/ Lan- } \\
\text { guage }\end{array}$ & $\begin{array}{l}\text { CRA/Reviewing/ } \\
\text { Language }\end{array}$ & $\begin{array}{l}\text { CRA/Reviewing/ } \\
\text { Language }\end{array}$ & $\begin{array}{l}\text { CRA/Reviewing/ } \\
\text { Language; } \\
\text { CRA/Releasing a } \\
\text { version }\end{array}$ \\
\hline \multicolumn{5}{|l|}{ Organizer } \\
\hline Content & $\begin{array}{l}\text { CRA/Content } \\
\text { organization; } \\
\text { CRA/Researching } \\
\text { \& Finding } \\
\text { Content; } \\
\text { CRA/Releasing a } \\
\text { version }\end{array}$ & & & $\begin{array}{l}\text { CRA/Releasing a } \\
\text { version }\end{array}$ \\
\hline Group & $\begin{array}{l}\text { GRA/Group } \\
\text { Formation; } \\
\text { GRA/Task } \\
\text { assignments and } \\
\text { changes; } \\
\text { GRA/Role } \\
\text { assigments and }\end{array}$ & & & \\
\hline \multicolumn{5}{|l|}{$\begin{array}{l}\text { Template De- } \\
\text { signer }\end{array}$} \\
\hline Interface & CRA/Templating & CRA/Templating & CRA/Teinplating & CRA/Templating \\
\hline
\end{tabular}




\begin{tabular}{|l|l|l|l|l|}
\hline $\begin{array}{l}\text { Role / Control- } \\
\text { ling }\end{array}$ & Centralized & Relay & Independent & Shared \\
\hline Pedagogical & CRA/Templating & CRA/Templating & CRA/Templating & CRA/Templating \\
\hline Accreditator & Accreditation & & Accreditation & Accreditation \\
\hline Translator & CRA/Translating & CRA/Translating & CRA/Translating & CRA/Translating \\
\hline
\end{tabular}

CRA $=$ Content-Related Activities, GRA = Group-Related Activities

\section{Granularity}

According to the Webster's Dictionary's etymology of the term granularity, "granule" comes from Late Latin granulum, diminutive of Latin granum (grain): a small particle, especially one of numerous particles forming a larger unit. Discussions about granularity arose when first dealing with Learning Objects (LO). LO granularity would refer to the degree of detail or precision contained in a LO, as well as its size, decomposability, and potential for reuse (Silveira et al, 2007). This dimension is considered in the scope of this project, as shown in Figure 8:

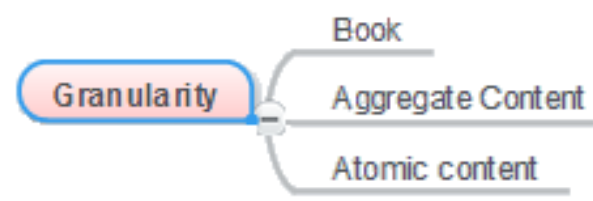

Figure 8. Granularity Dimension

Metadata standards consider different levels of granularity, called Aggregation Level. This term is used in IEEE Learning Object Metadata (IEEE-Standards Association, 2002) to describe "the functional granularity" of a learning object, classifying it in a four-stepped scale for aggregation level:

1. The smallest level of aggregation, e.g. raw media data or fragments.

2. A collection of level 1 learning objects, e.g. a lesson.

3. A collection of level 2 learning objects, e.g. a course.

4. The largest level of granularity, e.g. a set of courses that lead to a certificate

CISCO (Cisco Systems, 2003) identifies Reusable Learning Objects (RLOs) and Reusable Information Objects (RIOs). In its strategy, a RLO consist of an overview, a set of RIOs, a summary, or a practice. This view maps the terms "lesson" for a RLO and "topic" for a RIO (however, in the RLO's definition it says that many RLOs can be combined to form a lesson). A RIO is classified based on instructional purpose: concept, fact, process, principle, or procedure. Alternatively, Learnativity's Content Ecosystem is a hierarchy of Educational Objects, in which the Learning Objects are one specific type of Educational Objects. This hierarchy suggests four types of Educational Objects: Content Assets, Information Objects, Learning Objects, and Learning Components. A Content Asset can be any digital resource. With a little more context, an Information Object can be composed of several Content Assets, but its distinctive feature is that it must have an Instructional Type (e.g., exercise, example, simulation, or question). A Learning Object, in turn, may be composed of several Information Objects, but will only be a Learning Object if it has one Educational Objective. An Educational Objective consists of two parts: a verb and a noun (e.g., "motivate concerning the need for referential integrity", "understand the X algorithm", "measure the skills in conceptual modeling"). A Learning Component has several Learning Ob- 
jects, but its distinctive feature is that it follows an Instructional Strategy and has more than one Educational Objective. Thus, the main distinction between Educational Objects is not the aggregation level, nor the size in bytes, nor the duration; it is semantics. Semantics from an instructional point of view could be something like "1) Review for previous knowledge, 2) Motivate, 3 ) Understand, 4) Practice, and 5) Evaluate".

Following these considerations, we observe that the method to Content Generation in a textbook must be guided by the following point: Objects must be aggregated with an "instructional sense", which imposes restrictions on the way to generate content. In this sense, regarding the main context, which deals with open textbooks as the focus point of this methodology, the diverse levels of granularity proposed by Learnativity's Content Ecosystem could be, at the same time, resumed and expanded in order to support a theoretically infinite number of granularity levels, as well as to change the focus from the Learning Objects / Open Educational resources point of view to a more book-oriented, versioning-driven one. Figure 9 shows a UML Class Diagram that briefly presents this idea.

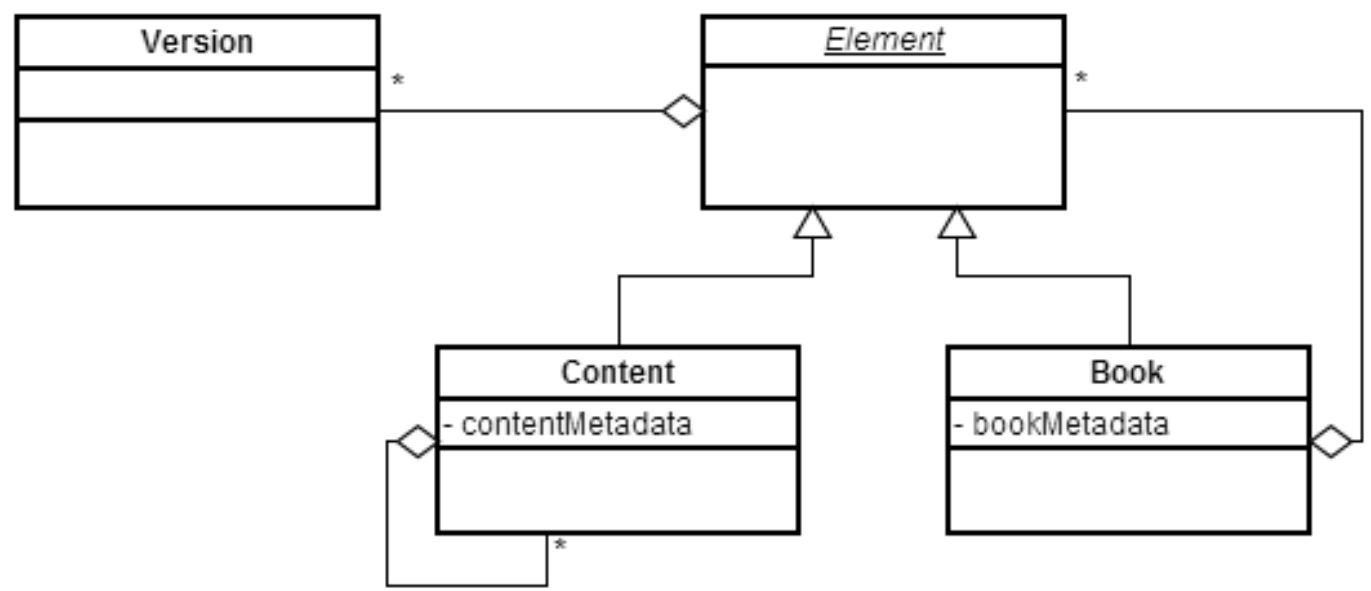

Figure 9. UML Class Diagram of LATIn supporting structure for open textbooks with heterogeneously-granular content

As seen in the diagram, metadata is an important part of any content. These metadata (which are meant to be distinct for contents and the books themselves) will be useful to manage adaptation to the different contexts of the Latin American Region.

\section{Writing Groups}

Writing groups are the different ways in which the members of the group cooperate together in the writing process. These three approaches are seen in Figure 10.

A more detailed description is added below.

- Single writer: In this strategy, one person writes and the rest play other roles in the group. There is only one content producer.

- Separate writers: In this strategy, the document is divided into parts and different individuals write the various parts. Here we have several content producers.

- Joint writing: In this strategy, several group members compose the text together, either synchronously or asynchronously. Even minute components of the text are decided by a group effort. 


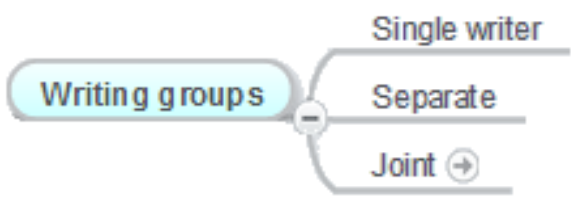

Figure 10. Writing groups Dimension

For our ecosystem of collaborative production, the three strategies are valid. Even in single writer, collaboration is incorporated. In a study by Posner and Baecker (1992), the single writer strategy was very popular. When used, a hierarchical difference among participants of the writing process was observed. A lower status member played the content producer role, while the higher status member would play the role of idea generator. The single writer role was also assigned to the individual most familiar with the required format or the structure of the final document. Some groups of the study use the single writer in order to have a uniformly written document. As mentioned before, the writing strategy is closely related with the process control. Use of the single writer strategy usually implies the use of centralized process control method. According to the same study, the separate writers strategy is also very popular in joint projects. By partitioning the document, the group can work in parallel, thereby speeding up the writing process. The study revealed time pressure was responsible for the use of the separate writers approach. Following the separate work, in most cases there still remains the need to unite the resulting segments in order to create a uniform style. That is why writing strategy is closely related with the different stages of writing process. Joint writing can have different effects on group cohesion and it depends on the maturity of the working group. An experienced group is able to work together more smoothly than a new group. Another important aspect leading to the success of the joint writing strategy is the document control method that is used with it. The respondents in the study used either shared, relay or independent control, the last proving to be the least successful combination.

\section{Conclusions}

This conceptual work describes and systematizes a methodology that consists of a digital ecosystem for the collaborative production of open textbooks. This approach has the potential to solve standing methodological problems with current initiatives such as Wikibooks and Connexions. The conceptualization of the collaborative environment as a digital ecosystem provides a fruitful analogy for the sharing and reusing of content by different book-creating and content-creating groups. It also promotes the idea of book production as a non-ending endeavor. This concept could result in higher quality and updated textbooks.

Group organization and productivity may be facilitated by providing content produced through collaboration models. This work presents six methodological dimensions. These dimensions, when combined, provide a flexible framework. Each writing group can select the combination of methodological dimensions that best fits their context.

In order for this suggested methodology to be tested, it needs to be fleshed out in a technological platform. This platform is planned to be built by the LATIn project for the collaborative creation of open textbooks in the Latin American region. To validate the efficacy of the proposed methodology framework, the platform and the implementation strategies, 144 Open textbooks will be collaboratively created by professors from each of the nine partner institutions. 16 books about different topics will be used by each one of the Latin American partners of the LATIn project. This pilot will be conducted to evaluate the proposed collaborative methodology for the creation of books.

The final test for this initiative will be its deployment in higher educational institutions. This adoption will be supported by a strategy that promotes the digital ecosystem and its benefits for institutions, professors, teachers, content producers, and students. 


\section{Acknowledgements}

The authors acknowledge for the support by the European Union through project Alfa III: DCIALA/19.09.01/11/21526/279-155/ALFA III (2011)-52.

\section{References}

Baecker, R. M., Grudin, J., Buxton, W. A. S., \& Greenberg, S. (1995). Readings in human-computer interaction: Towards the year 2000 (2nd ed.). San Francisco, California: Morgan Kaufmann Publishers.

Baker, J., Thierstein, J., Fletcher, K., Kaur, M., \& Emmons, J. (2009). Open textbook proof-of-concept via Connexions. Connexions, USA. International Review of Research in Open and Distance Learning, 10(5). Retrieved from http://www.irrodl.org/index.php/irrodl/article/viewArticle/633

Boley, H., \& Chang, E. (2007). Digital ecosystems: Principles and semantics. IEEE International Conference on Digital Ecosystems and Technologies. Cairns, Australia. February 2007. NRC 48813.

Briscoe, G., \& De Wilde, P. (2006). Digital ecosystems: Evolving service-orientated architectures. Proceedings of BIONETICS '06 the 1st International Conference on Bio Inspired Models of Network, Information and Computing Systems. ACM New York, NY, USA.

Cabeda, M. (2005). O chat-fórum: uma idéia de uso híbrido, síncrono e assíncrono, através de uma única ferramenta normalmente assíncrona, o fórum virtual [The chat-forum: An idea to use hybrid, synchronous and asynchronous, through a single tool usually asynchronous, the virtual forum]. Proceedings of Congresso Internacional de Educação à Distância, 12, 18-22 set. 2005. Educação à Distância e a Integração das Américas. Retrieved Nov 5th 2012 from http://www.abed.org.br/congresso2005/por/pdf/121tcc3.pdf

Cisco Systems. (2003). Reusable learning object strategy: Designing and developing learning objects for multiple learning approaches. Retrieved April 5, 2011 from http://www.enovalia.com/materiales/RLOW_07_03.pdf

Chang, E., \& West, M. (2006). Digital ecosystems: A next generation of the collaborative environment. Proceedings of the Eighth International Conference on Information Integration and Web-based Applications \& Services. December 2006, Yogyakarta Indonesia.

Dholakia, U. M., King J. W., \& Baraniuk R. (2006). What makes an open education program sustainable? The case of Connexions. Organisation for Economic Co-operation and Development. Retrieved from http://www.oecd.org/dataoecd/3/6/36781781.pdf

Ferreira, A. B. H. (1986). Novo dicionário da língua Portuguesa [New dictionary of the Portuguese language] (2nd ed.). Rio de Janeiro: Nova Fronteira.

Frith, J. (2009). The open revolution: An environmental scan of the open textbook landscape. Raleigh, NC: NCSU Libraries Digital Scholarship \& Publishing Center.

Henderson, S. (Project Director), \& Nelson, D. (Project Manager). (2011). The promise of open access textbooks: A model for success. Available from http://www.openaccesstextbooks.org

Hohne, D., Fu, L., Barkel, B., \& Woolf, P. (2007) AC 2007-2074: The Wiki approach to teaching: Using student collaboration to create an up-to-date open-source textbook. University of Michigan: American Society for Engineering Education.

Horner, M., \& Blyth, S. (2008). How to collaboratively develop open-source textbooks (in hindsight!). Free High School Science Texts. Available from www.fhsst.org

Howe, J. (2006). The rise of crowdsourcing. Wired, 14(6). Retrieved from http://www.wired.com/wired/archive/14.06/crowds.html

IEEE-Standards Association. (2002). Draft standard for learning object metadata. Retrieved from http://ltsc.ieee.org/wg12/20020612-Final-LOM-Draft.html 
Noel, S., \& Robert, J. (2004). Empirical study on collaborative writing: What do co-authors do, use, and like? Computer Supported Cooperative Work, 13, 63-89.

Ochoa, X.; Silva-Sprock, A.; \& Silveira, I. F. (2011). Collaborative open textbooks for Latin America - The LATIn project. International Conference on Information Society (i-Society), pp.398-403, 27-29 June 2011

Patel, H., Pettitt, M., \& Wilson, J. R. (2012). Factors of collaborative working: A framework for a collaboration model. Applied Ergonomics, 43(1), 1-26. doi:10.1016/j.apergo.2011.04.009

Posner, I., \& Baecker, R. (1992). How people write together. Proceedings of the $25^{\text {th }}$ Hawaii International Conference on System Sciences, IV, 127-137.

Ravid, G., Kalman, Y. M., \& Rafaeli, S. (2008). Wikibooks in higher education: Empowerment through online distributed collaboration. Computers in Human Behavior, 24(5), 1913-1928.

Silveira, I. F., de Araújo, C. F., Amaral, L. H., de Oliveria, I. C. A., Schimiguel, J., Ledón, M. F-P., \& Ferreira, M. A. G. V. (2007) Granularity and reusability of learning objects. In A. Koohang \& K. Harman (Eds.). Learning objects and instructional design (pp. 139-170). Santa Rosa, CA, USA: Informing Science Institute.

\section{Biographies}

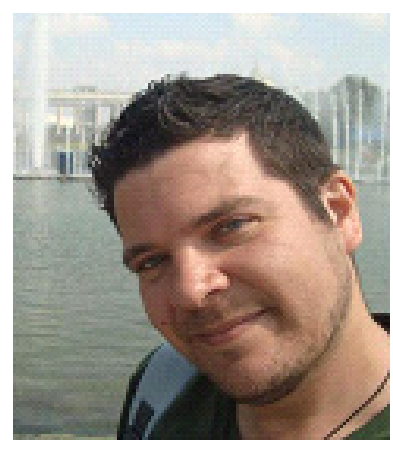

Ismar Frango Silveira received his $\mathrm{PhD}$ in Electrical Engineering at the University of São Paulo (USP), his MSc. degree in Computer Sciences at Technological Institute of Aeronautics (ITA), and his BSc. in Mathematics at Federal University of Juiz de For a (UFJF), all in Brazil. Nowadays he is a Professor at Mackenzie Presbyterian University and Cruzeiro do Sul University, both in São Paulo, Brazil, teaching in $\mathrm{CS}$ and Digital Games undergraduate courses and MSc. and PhD. programs on Math \& Sciences Teaching and Electrical Engineering. Currently, he is the national coordinator of Computers in Education Comission of Brazilian Computer Society (SBC).

Email: ismarfrango@gmail.com

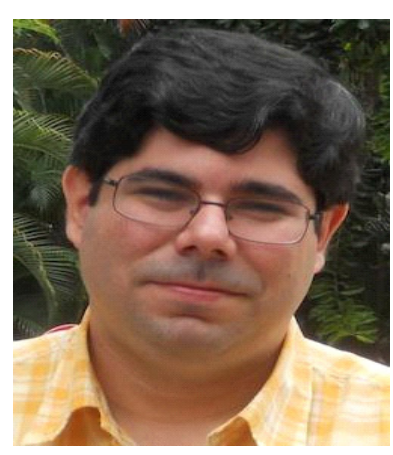

Xavier Ochoa is a Principal Professor at the Faculty of Electrical and Computer Engineering at Escuela Superior Politécnica del Litoral (ESPOL) in Guayaquil, Ecuador. He coordinates the research group on Teaching and Learning Technologies at the Information Technology Center (CTI) at ESPOL. He is also involved in the coordination of the Latin American Community on Learning Objects (LACLO), the ARIADNE Foundation, and several regional projects. His main research interests revolve around Learning Technologies, Learning Analytics and Infometrics. Email: xavier@cti.espol.edu.ec 


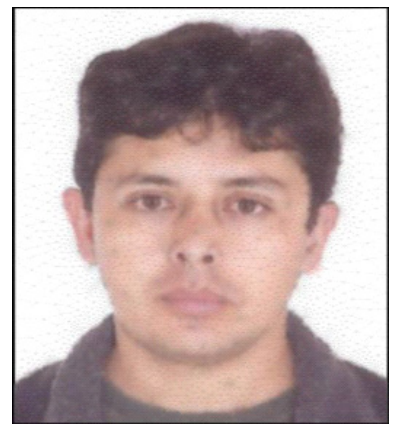

Alex J. Cuadros-Vargas received the degree of PhD. [2002-2006] and Master [2000-2001] in Mathematics and Computer Science at the University of Sao Paulo, Brazil. He conducted a Post-Doctoral program [2007-2008], researching mesh generation from images, also at the University of Sao Paulo. Alex was a visiting scholar [February-March 2009] in Department of Radiology, University of Pennsylvania (UPENN), USA. He was also a visiting professor [in December 2009, February-2010] in Scientific Computing and Imaging Institute (SCI) at Utah State University, USA. He is a research professor at San Pablo Catholic University in Arequipa, Peru [from February 2009] and coordinator of the Center for Research in Computer Science [since March 2013]. Alex is a founding member of the Peruvian Society of Computing (SPC). Email: alex.jcv@gmail.com

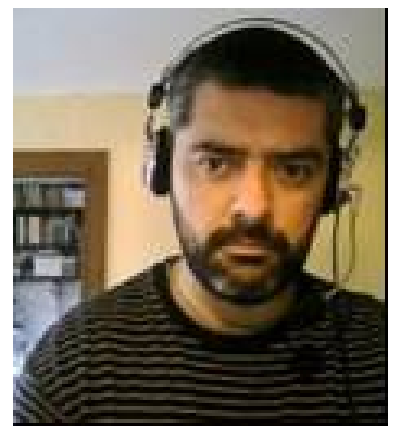

Alén Humberto Pérez Casas received his Master degree in Sociology in 2004 at UdelaR - Universidad de la República, Uruguay, the same place where he completed his undergraduate course in 1992. Currently, he is a $\mathrm{PhD}$ student in the same area and university, where he also works as coordinator of the Department of IT applied to Education, being responsible for all learning platforms of such University. Email: alen.perez@cse.edu.uy

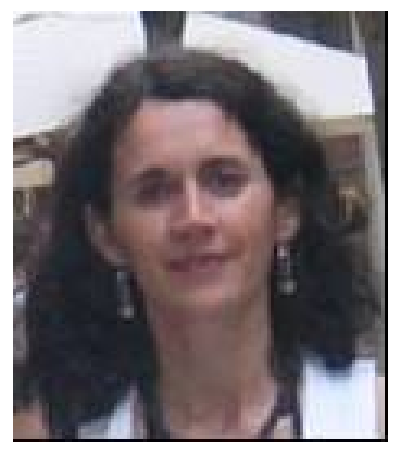

Ana Casali received her $\mathrm{PhD}$ and her Master degree in Information Technologies at the University of Girona, Spain, and she obtained her degree in Mathematics at the Universidad Nacional de Rosario (UNR), Argentina. She is Head of the Computer Science Department since 2007 and Professor at the Facultad de Ciencias Exactas, Ingeniería y Agrimensura, UNR since 1991. Also, she is researcher in the Centro Internacional Franco Argentino de Ciencias de la Información y de Sistemas (CIFASIS). She has worked in several international cooperation research projects and her research interest includes agent architectures, knowledge representation, approximate reasoning, and recommender systems and its applications to education. She also is author of many research articles mainly in the field of Artificial Intelligence and its applications. Email: anacasali@gmail.com

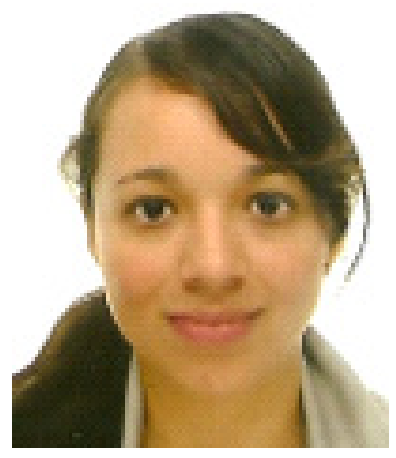

André Ortega is a Computer Engineer and holds a Master degree in Information Technologies from the Polytechnic University of Madrid. She is currently working as project leader in the research group on Teaching and Learning Technologies at the Information Technology Center (CTI) at ESPOL. Her main research interests revolve around Information Security, High Performance Computing, and Learning Technologies. Email: andre.ortega@cti.espol.edu.ec 


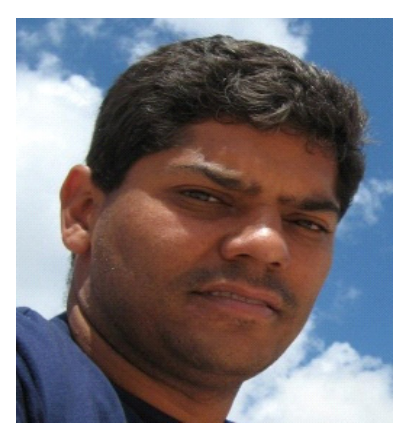

Antonio Silva Sprock is a PhD student of Computer Science of the Universidad Central de Venezuela and MSc in Knowledge Engineering from the Polytechnic University of Madrid. He is also a professor and researcher at the School of Computer in Science Faculty in the Universidad Central de Venezuela. From 2010-2012 he was coordinator of the Latin American Community of Learning Objects (LACLO) in the RedCLARA. Since 2012, he coordinates locally the LATIn project (Latin American Open Textbook Initiative), ALFA III project, funded by the European Union. His research areas include DataBase, Information System, and Learning Objects. He is author of many research publications in conferences and journals. Email: asilva.sprock@gmail.com

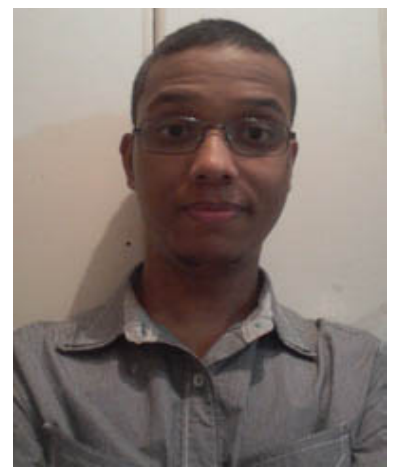

Carlos Henrique Alves Silva is an English teacher, a Computer Programming Technician, and an undergraduate student attending the Computer Information Systems course at Mackenzie Presbyterian University in São Paulo, Brazil. Currently, he is enrolled in an interchange undergraduate program at Goldsmiths, University of London. Email: carlos alvers@hotmail.com

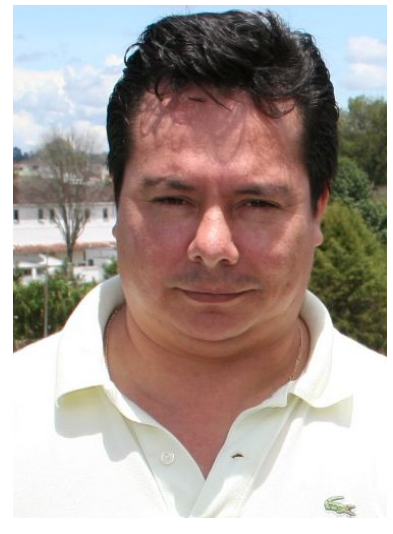

Cesar Alberto Collazos Ordoñez is a Full Professor at University of Cauca-Colombia. $\mathrm{PhD}$ in Computer Science, his research areas include HCI, CSCL, and CSCW. He is the author of many research publications in conferences and journals. Email: ccollazo@unicauca.edu.co

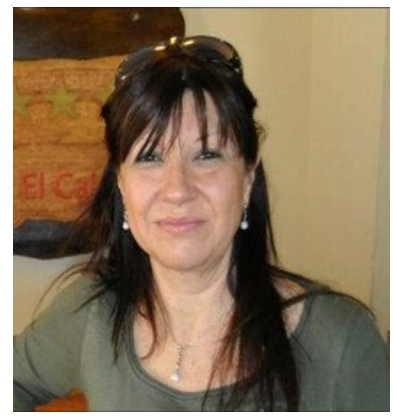

Claudia Deco is Doctor in Engineering, Universidad Nacional de Rosario, and she has a Master Degree in Computer Science, Universidad de la República, Montevideo, Uruguay. She obtained her degree in Mathematics at the Universidad Nacional de Rosario. She is also a professor and researcher at the Research Department, Facultad de Química e Ingeniería, Rosario, Universidad Católica Argentina. Furthermore, she coordinates the Research Group of Databases at the Facultad de Ingeniería, Universidad Nacional de Rosario. Her research interest includes Databases Technologies and Information Retrieval. She participates in scientific events as a member of the conference program committee and as a reviewer of some papers and journals. She also is author of many research articles, mainly in this area. Email: deco.clau@gmail.com 


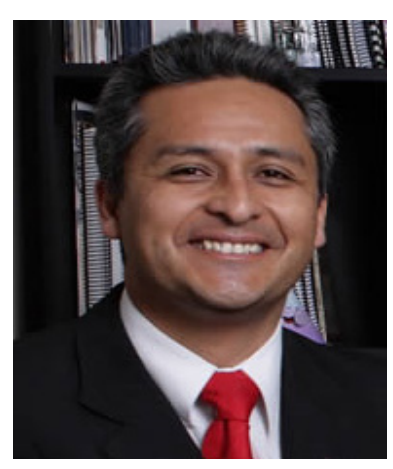

Ernesto Cuadros-Vargas earned his $\mathrm{PhD}$ degree in Computer Science, University of Sao Paulo 2004 in joint projects with Carnegie Mellon University 2001 and the Technische Universitat Berlin in Germany. Currently he is Executive Secretary of the Latin American Studies in Informatics (CLEI), being the unique Latin American member of the world team IEEE / ACM that proposes regulations for Computer courses (CS2013). He also is Dean of the Faculty of Engineering and Computing of San Pablo Catholic University at Arequipa, Peru. He was President of the Peruvian Society of Computing (SPC) from 20012008 and 2010. Email: ecuadros@gmail.com

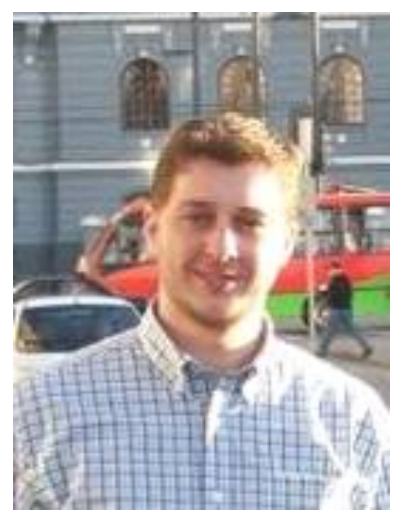

Everton Knihs is a $\mathrm{PhD}$ student in Electrical Engineering at Universidade Prebisteriana Mackenzie, Brazil and also has Law studies at Faculdades Metropolitanas Unidas. He has a Master degree in Mathematics Teaching, earned at Cruzeiro do Sul University, in Brazil. Email: tomspsp@gmail.com

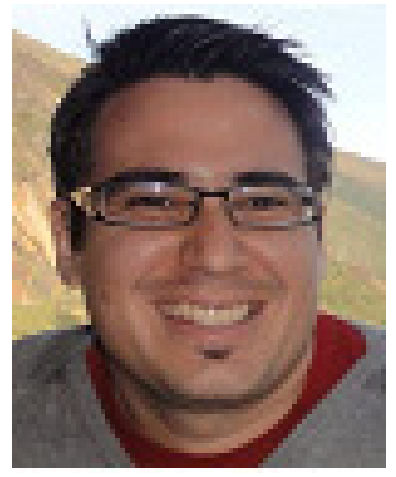

Gonzalo Parra is a researcher at the Human-Computer Interaction group from the Computer Science department of the Katholieke Universiteit Leuven, Belgium. His research interests include metadata generation and manipulation, flexible access to information based on open standards, mobile technologies, user experience and personalization. Parra has been involved in different EU projects, such as: MACE, ASPECT, ICOPER and STELLAR. Email: gonzalo.parra@,cs.kuleuven.be

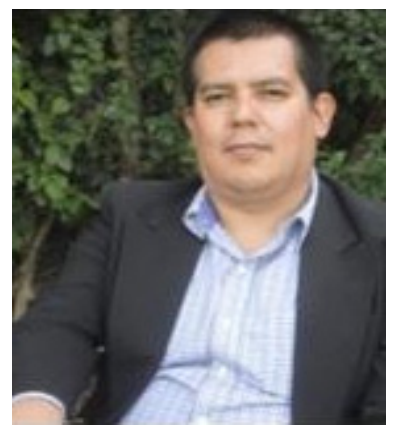

Jaime Muñoz-Arteaga is a professor at the Universidad Autónoma de Aguascalientes in Aguascalientes México. He holds a Ph.D. in Computer Science at the University Toulouse 1, Toulouse, France. He has reported his work in several journals, books, and conference papers. His current research interests include topics such as Human-Computer Interaction, e-learning, and Software Engineering.

Email: jmauaa@gmail.com 

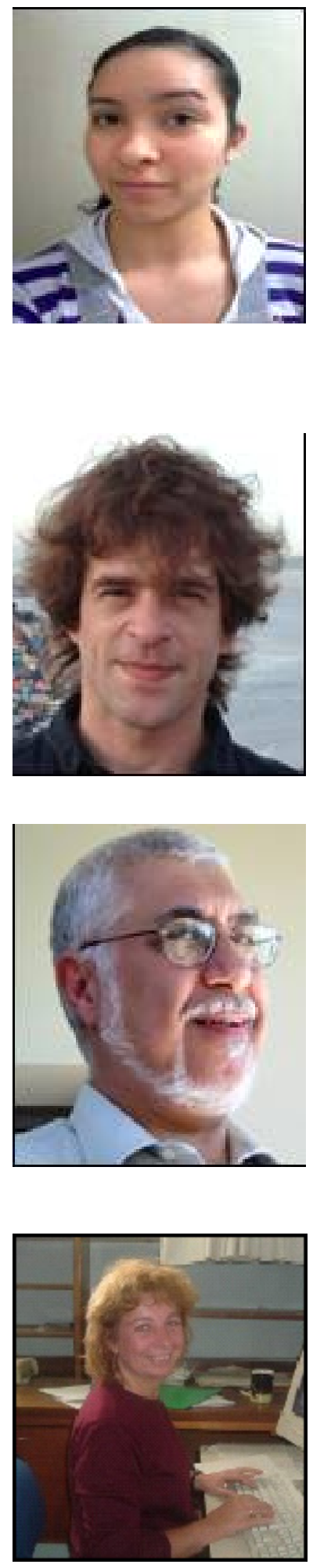

Jessica Gomes dos Santos is a Computer Programming Technician and an undergraduate student attending the Computer Information Systems course at Mackenzie Presbyterian University in São Paulo, Brazil. Currently, she is enrolled in an interchange undergraduate program at Brunel University, in United Kingdom.

Email: jeh.g.santos@,gmail.com

Julien Broisin is an Assistant Professor at the Toulouse University, France. He leads his research activities at the Computer Science Research Institute of Toulouse (http://www.irit.fr), and is particularly interested in the design and management of personalized and adaptive web-based learning environments. Email: broisin@irit.fr

Nizam Omar holds the degrees of BSc in Mechanical Engineering (1974) and MSc in Applied Mathematics (1979), both at the Technological Institute of Aeronautics - ITA and Ph.D. in Computer Science at Pontifical Catholic University of Rio de Janeiro (1989). Professor of ITA (retired), he is currently Professor at the University Mackenzie. He has experience in the area of Computer Science, with an emphasis on Computer Theory, Artificial Intelligence, Formal Languages, and Automata, acting on the following topics: intelligent tutors, adaptive didactics, expert systems, neural networks and learning environments. Email:nizamomar51@gmail.com

Regina Motz received her $\mathrm{PhD}$ in Computer Science at University of Darmstadt, Germany, her MSc. degree in Computer Sciences at Federal University of Pernambuco, Brazil, and her BSc. in Computer Engeneering at Universidad de la República, Uruguay. Nowadays, she is Full Professor at Universidad de la República, Uruguay, teaching in CS undergraduate courses and MSc. and $\mathrm{PhD}$. programs on Computer Sciences. Email: regina.motz@gmail.com 


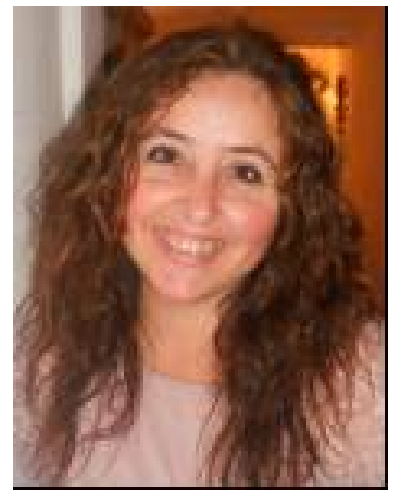

Virginia Rodés is Bachelor in Communication Sciences, University of the Republic, UdelaR, Uruguay. She is specializes in Virtual Learning Environments at OEI / Virtual Educa. She is currently is finishing her MSc in Education at University of the Republic, where she works as a Professor. She has worked as a university lecturer in different areas (Bachelor of Communication Studies, Faculty of Engineering, Faculty of Law, Faculty of Economics and Administration, Training Unit of UdelaR officials), being responsible for training and advising teachers in the pedagogical design of educational materials and communication courses, development of technology integration in teaching and incorporating blended and distance education quality. She has also worked in institutions and organizations related to environment, health and education, like IMM, MEF, and acted as a consultant for IDB, UNDP and UNESCO. She has authored papers and publications in her areas of interest (education, technology-enhanced education, distance education, science, technology and society, and gender issues). Email: virginia.rodes@cse.edu.uy

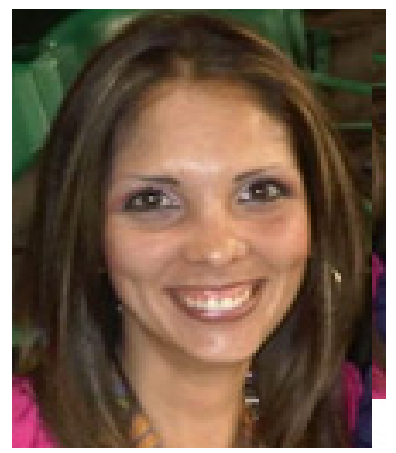

Yosly C. Hernandez Bieliuskas is a PhD Student in Education, University of Los Andes (ULA), Venezuela; MSc and BSc in Computer Sciences, Central University of Venezuela (UCV), Venezuela. She is a senior Professor and Researcher, Distance Education Unit and Computer Sciences School, Central University of Venezuela. She currently teaches in Undergraduate and Graduate Programs, as well as Distance Teachers Formation Programs and Courses. She is an Active Researcher in B Cathegory, accredited in the Program of Research Stimulation from National Observatory of Science, Technology and Innovation of the Ministry of People's Power of Science, Technology and Intermediate Industries. Email: yosly.hernandez@,ciens.ucv.ve 